\title{
A Geographical Analysis of Positioning and Functionality of the Tank Cascade Systems of the North Central Province
}

\section{Sri Lanka}

\author{
by \\ Ganthihe Mudiyanselage Bandaranayake
}

Thesis submitted to the University of Sri Jayewardenepura for the award of the Degree of Doctorate of Philosophy in Geography 


\section{Declaration}

The work described in this thesis was carried out by me under the supervision of Marcus M. Karunanayake, Emeritus Professor of Geography University of Sri Jayewardenepura and Professor Lennart Strömquist, Department of Social and Economic Geography, University of Uppsala, Sweden and a report on this has not been submitted in whole or in part to any university or any other institution for another Degree/ Diploma.

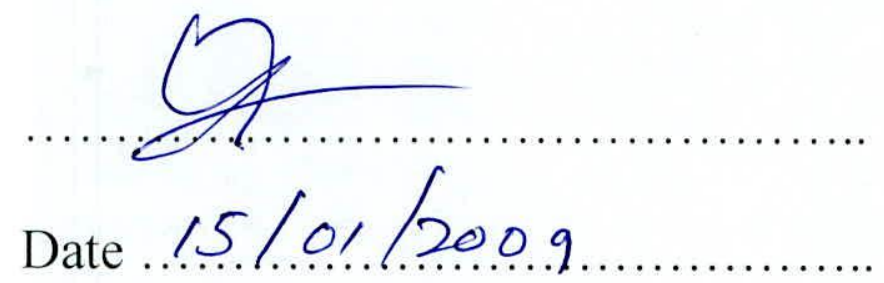

Ganthihe Mudiyanselage Bandaranayake

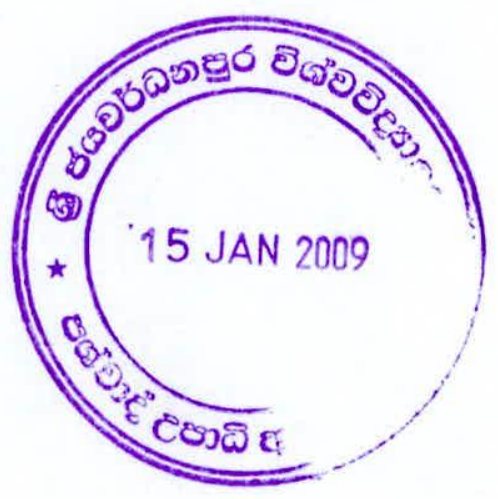




\section{Certification}

We certify that the above statement made by the candidate is true and that this thesis is suitable for submission to the Universily for the purpose of evaluation.

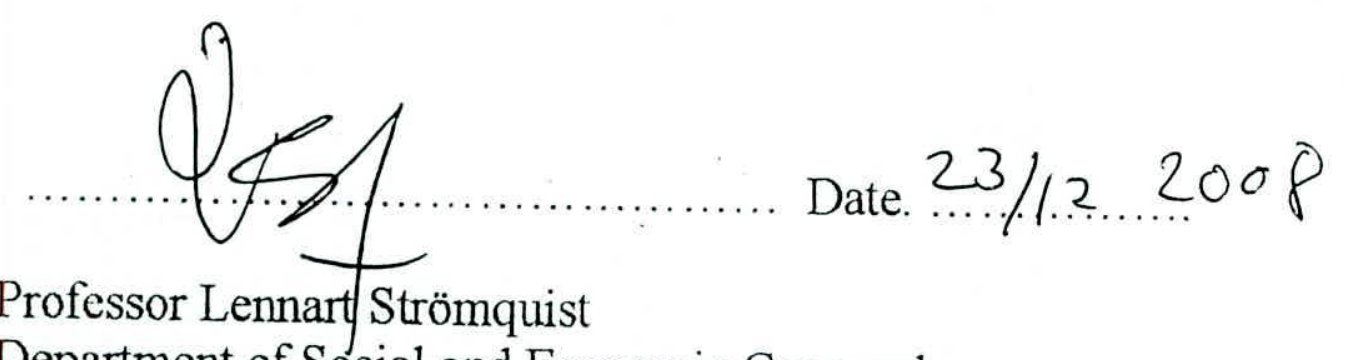

Department of Social and Economic Geography

University of Uppsala

Sweden

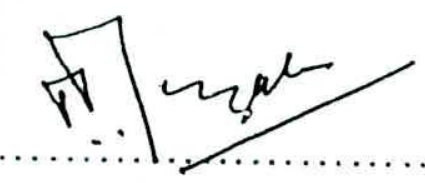
Date..17. $-12-2008$

Marcus M. Karunanayake

Emeritus Professor of Geography

University of Sri Jayewardenepura

Sri Lanka

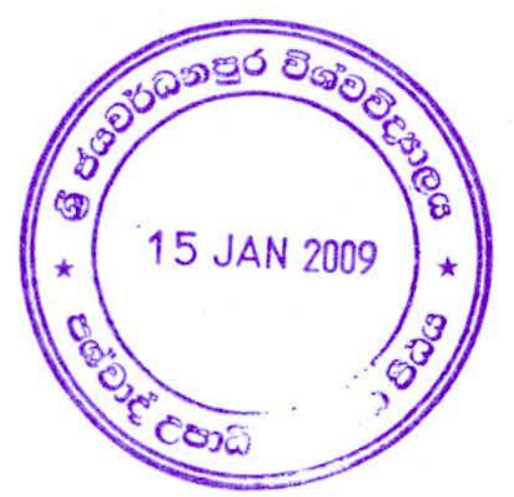




\section{Acknowledgements}

First I am extremely grateful to my supervisors, Marcus M. Karunanayake, Emeritus Professor of Geography, University of Sri Jayewardenepura, who encouraged me to focus my interest on the field of hydrology and water resources and gave me invaluable guidance with progressive comments in supervising this thesis and Professor Lennart Strömquist, Department of Social and Economic Geography, University Uppsala, who gave me technical advice and provided materials and relevant computer programs for GIS application for this study.

I would like to express my gratitude to Dr.Clas Lindberg, the Coordinator of the

Sida/SAREC Research Program who was responsible for coordinating the programs on behalf of the Department of Social and Economic Geography Uppsala University to pursue my studies in Sweden.

I would like to appreciate the help given by the Director and staff of the Agricultural Research Station, Maha Iluppallama who provided me climatic data and practical guidelines in the use of instruments.

The kind cooperation received from the International Water Management Institute (IWMI) Colombo and the Department of Irrigation in permitting me the use of library facilities and assisting in making personal contacts with scientists who are engaged in research in the same field is much appreciated. 
I also wish to acknowledge Dr.T. Turpin, the Director and the Landscape Ecologists Nicholas Pearson Associates in the United Kingdom who helped me by reading the initial manuscript and giving technical advice.

I highly appreciate the help received from Ms. E. A. Thiruppathy in reading the final manuscript and in setting up of the total thesis very neatly.

Finally, I appreciate the cooperation received from my wife and sons, who were a constant source of encouragement for me in this attempt. 


\title{
Acronyms
}

\author{
AWA -Actual Water Available area \\ DSWY -Dry Season Water yield \\ DST -Down Stream Tank \\ IWMI -International Water Management Institute \\ LHG -Low Humid Gley Soil \\ NCP -North Central Province \\ RBE $\quad$-Reddish Brown Earth soil \\ TCS -Tank Cascade Systems \\ TTC -Total Tank Capacity \\ UST -Upper Stream Tanks \\ WSA -Water Spread Area \\ WSWY -Wet season Water Yield \\ CWY -Cascade Water Yield \\ SVI -Spectral Vegetation Indices \\ WSA -Water Spread Area \\ TWSA -Total Water Spread Areas \\ AWAA -Actual Water Available Area \\ TWI -Tank Water Intake
}




\section{Glossary of terms}

Dryness of catchments. The dry status of the tank catchments shown by the dried-up vegetation

Cascade water yield. The water amount gained by the catchment of the cascade after the balance from rainfall input and evaporation loss

Tank density.

The number of tanks per unit of area or the ratio of tanks to the area of cascade

Dried-up tank beds. $\quad$ Tank beds without water and with dried -up vegetation

Dried -up vegetation. The vegetation characterized by permanently or temporally wilted, dead or with removed leaves

Water spread area. The tank's denudation area

Actual water available The tank's water area exists at the moment of investigation area.

Water sufficiency. The availability water in any quantity in the driest month

Effective cascade. Cascades which have a surplus water after filling all the tanks with the cascade water yield or showing any water quantity of water in the majority of tanks

Efficiency of cascade. The availability of water exists in the majority of tanks in the cascade 


\section{CONTENTS}

\section{Abbreviations \\ Glossary of terms \\ Abstract}

Chapters 1-8

1. Introduction.

1.1. Dams and reservoirs

1.2. Tank cascades

1.3. Hydrology of cascades

1.4. Systems theory system approach and tank cascades

1.5. Physical background

1.6.1. Conceptualization and theoretical framework

1.6.2. Approach to the study

1.7. Literature review

1.8. Objectives

2. Methodology

2.1.1. Data collection and measurements

2.1.2. Use of climatic data

2.1.3. Social information and oral data

2.2.1. Definitions and parameters

2.2.2. Water yield

2.2.3. Tank water intake

2.2.4. Cascade water surplus and deficit

2.2.3. Dryness of the catchments

2.2.4. Water efficiency

2.2.5. Dryness of the catchments

2.2.6. Water efficiency

2.2.7. Dried-up vegetation.

2.3. Study Area

3. Spatial dimension of tank cascade systems

3.1. Distribution of cascades

3.2. Geology, landform, topography and cascade distribution

3.3. Drainage systems and cascades

3.4. Tank density

3.5. Spatial dimension of cascades in the local landscape

3.6. Topology of cascades and classification

3.7. Functional characteristics of cascades 
4.1. Sample cascades

4.2. Cascade A

4.2.1. Positioning of cascade A in relation to the Nachchaduwa reservoir

4.3. Cascade B

4.3.1. Positioning of cascade A in relation to the Nachchaduwa reservoir

4.4. Cascade C

5. The status of tanks in the dry and wet seasons

5.1. Status of tanks in cascade A at the end of the dry season in 1994

5.2. Status of water availability in and around the tanks of the cascade A in 1994

5.3. Status of tanks in cascade $A$ at the end of the 2001 dry season

5.4. Status of water availability in and around the tanks of the cascade A in 2001

5.5. Status of tanks in cascade $A$ at the end of the wet season in 2006

5.6. Status of tanks in cascade B at the end of the 1994 dry season

5.7. Status of water availability in and around the tanks of cascade B in1994

5.8. Status of tanks in cascade B at the end of the 2001 dry season in 2001

5.9. Status of water availability in and around the tanks of the cascade B in 2001

5.10. Status of tanks in cascade $\mathrm{C}$ at the end of the 1994 dry season

5.11. Status of water availability in and around the tanks of the cascade C in 1994

5.12. Status of tanks in cascade $\mathrm{C}$ at the end of dry season in 2001

5.13. Status of water availability in and around the tanks of cascade $C$ in 2001

5.14. Status of tanks in cascade $C$ at the end of the wet season in 2006

5.15. Dryness of the catchment environments.

5.16. The Dryness of tank catchments of the cascade A in 1994

5.17. The Dryness of tank catchments of the cascade A in 2001

5.18. The Dryness of tank catchments of the cascade B in 1994

5.19. The Dryness of tank catchments of the cascade B in 2001

5.20. The Dryness of tank catchments of the cascade C in 1994

5.21. The Dryness of tank catchments of the cascade C in 2001

\section{Cascade water yield, tank water availability and} water efficiency

6.1. Water movements and the water yield of tanks cascades

6.2. Water yield of the cascade A at the end of the dry season in 1994

6.3. Water yields of the cascade $\mathrm{A}$ in 2001

6.4. Water yield of the cascade A in 2006

6.5. Water yield of the cascade B at the end of the dry season in 1994 
6.6. Water yields of the cascade B in 2001

6.7. Water yield of the cascade B in 2006

6.8. Water yield of the cascade $\mathrm{C}$ at the end of the dry season in 1994

6.9. Water yields of cascade $\mathrm{C}$ in 2001

6.10. Water yield of cascade $\mathrm{C}$ in 2006

6.11. Cascade tank intake index

6.12. Tank water intake of cascade A in 1994

6.13. Tank water intake of cascade A in 2001

6.14. Tank water intake of cascade A in 2006

6.15. Tank water intake of cascade B in 1994

6.16. Tank water intake of cascade B in 2001

6.17. Tank water intake of cascade B in 2006

6.18. Tank water intake of cascade C in 1994

6.19. Tank water intake of cascade $\mathrm{C}$ in 2001

6.20. Tank water intake of cascade $\mathrm{C}$ in 2006

7. System functionality of cascades and water efficiency

$.193-210$

7.1. Position of tanks and the functionality of the cascade A

7.2. System functionality of the cascade A and water efficiency

7.3. Position of tanks and the functionality of the cascade $B$

7.4. System functionality of cascade B and water efficiency

7.5. Position of tanks and the functionality of the cascade $\mathrm{C}$

7.6. System functionality of cascade $\mathrm{C}$ and water efficiency

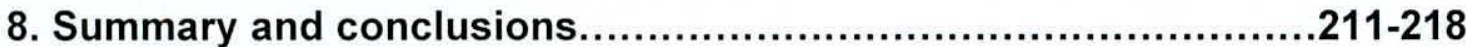

List of Tables

List of Figures and Plates

References

Appendices 


\section{List of Tables}

2.1 General rainfall regimes and climatic conditions of the Dry Zone

Page according to Sirinanda (1983

3.1 Distribution of cascades per Province

3.2 Cascade distribution within the North Central Province

58

59

3.3 The distribution of cascades according to river basins.

60

3.4 The distribution of tanks according river basins

62

3.5 Location of cascades in the NCP

65

3.6 Cascade tank density of NCP

3.7.1 Size class categories of cascades according to Panabokk

68

3.7.2 Cascade classification based on cropping intensity, after Panabokke

3.8. Classification of cascades using multi criteria made by Witharana (2004

5.1 Stream-wise distribution of tanks in Cascade A

5.2. Water status in and around the tanks of cascade A in 1994

5.3 Water availability of the tanks in the cascade A in 1994.

5.4 Status of each tank of the cascade A in September 2001

5.5. Status of water in and around the tanks of cascade A in 200

5.6. Water areas of tanks of the cascade A in 1994 and 200

5.7. Water level deviation from mean level of each tank in the cascade $\mathrm{A}$ in 2006

5.8. Functional status of tanks in cascade A in the rainy season (2006

5.9 Stream-wise distribution of tanks in the cascade B in 1994

5.10 Status of tanks in cascade B at the end of the dry season in 1994

5.11 Status of water availability of tanks in cascade B in 1994

5.12 Physical characteristic of the cascades of studied (Panabokke, C.R. )

5.13 Status of water availability of tanks in cascade B in 2001

5.14 Location of tanks in the stream valleys

5.15 Status of tanks in the cascade C in 1994

5.16 Water status of tanks in the cascade C in 1994

5.17 Status of tanks in the cascade $\mathrm{C}$ at the end of the dry season in 2001

5.18 Water condition in each tank of the cascade C

5.19 Changes occurred in the water spread areas of tanks cascade $\mathrm{C}$

5.20 Working and abandoned tanks in the cascade $\mathrm{C}$ in different year

5.21 Dryness of vegetation of tank catchments in the cascade A in 1994

5.22 Actual water available areas of tanks and the dryness of vegetation in tank catchments of the cascade A in 1994

5.23 Status of vegetation in tank's catchment of the cascade A in 2001

5.24 Dried-up vegetation covers of tank's catchments of the cascade B in 1994

5.25 Dried-up vegetation covers of tank's catchments of the cascade C in 2001

5.26 Dried-up vegetation covers of tank's catchments of the cascade C in 1994 
5.28 Changes in the catchments areas of rehabilitated tanks by 200

5.29 Functional status, water availability, dried-up vegetation and the

efficiency of cascades

6.1 Rainfall data and water yield of cascade A in 1994

6.2 Water yield of cascade A in the dry and wet seasons in 2001

6.3 Water yields of cascade A in 2006

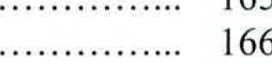

6.4 Water yield of cascade B in the dry and wet seasons in 1994

6.5 Water yield of Cascade B 2001

6.6 Water yield of cascade B in 2006

6.7 Water yield of cascade $\mathrm{C}$ in 1994

6.8 Water yield of cascade $\mathrm{C}$ in 2001

6.9 Water yield of cascade $\mathrm{C}$ in 2006

6.10 Water yields of sub-cascades of the cascade C in 1994

6.11 Tank Water intake of the cascade A in 1994

6.12 Tank Water holding capacities of the cascade A in 1994.

6.13 Tank Water intake of the cascade A in 2001

6.14 Tank water intake of cascade A in 2006

6.15 Changes of tank water holding capacities of the cascade A in 2006

6.16 Tank water intake of cascade B in 1994

6.17 Tank Water holding capacity of cascade B in 1994

6.18 Tank water intake of cascade B in 2001 and 1994

6.19 Tank water capacity of cascade B in 2001

6.20 Tank water intake of the cascade B in 2006

6.21 Tank water capacities of the cascade B in 2006

6.22 Tank water capacity of the cascade C in 1994

6.23 Total tank water capacities of the cascade C in 1994

6.24 Tank water capacity of cascade $\mathrm{C}$ in 2001

6.25 Total tank water holding capacity of the cascade C in 2001

6.26 Tank water intake of cascade $\mathrm{C}$ in 2006

6.27 Total tank water holding capacities of cascade C

6.28 Tank water intake and water efficiency

7.1 Position of tank in the cascade A

7.2 System functionality of the cascade A in 2006 in major (Maha) season

7.3 Position of tank in the cascade B

7.4 System functionality of the cascade A in 2006 in major (Maha) season

7.5 System functionality and the cascade efficiency 


\section{List of Figures and Plates}

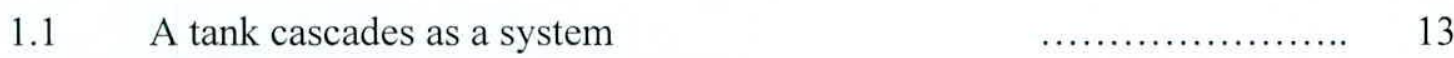

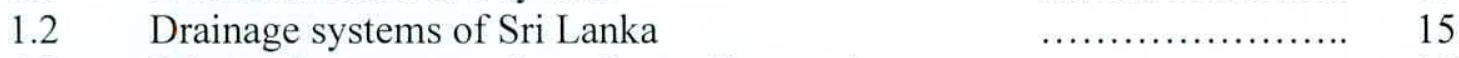

1.3 Schematic representation of a small cascade $\quad \ldots \ldots \ldots \ldots \ldots \ldots \ldots . \ldots \ldots$

$1.4 \quad$ A model of a cascade showing destination points of $\quad \ldots \ldots \ldots \ldots \ldots \ldots \ldots . . . . . . .19$ water flow

2.1 Rainfall pattern of the Dry Zone according to the $\quad \ldots \ldots \ldots \ldots \ldots \ldots \ldots . . . \ldots \ldots$ Hydrological year

2.2 Drainage and watersheds of the Anuradhapura $\quad \ldots \ldots \ldots \ldots \ldots \ldots \ldots . . \ldots 5$ district

2.3 Study area

3.1 Aerial view of the distributional pattern of tank cascades

3.2 Cascade distribution according to river basins

3.3 Geology and cascade distribution as shown in Landsat Image

3.4 Thematic map showing landforms and cascade distribution

3.5 Tanks distribution according Cook

3.6 Different shapes of cascades

3.7 Typical single and interconnected cascades

3.8.1 A model showing cumulative increase of tank capacity of a cascade

3.8.2 Cumulative storage cascades

4.1 Nachchaduwa drainage and sample cascades of the study

4.2 Cascade A and its destination tanks

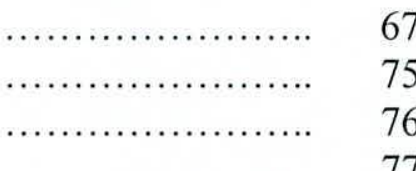

77

78

81

4.3 Drainage and tanks in the cascade A

4.4.1 Pahalawewa sub cascade

4.4.2 Location of tanks and the shape the Pahalawewa sub cascade

4.5.1 Mahakanumulla sub cascade

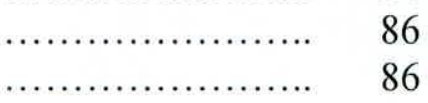

4.5.2. Location of tanks and the shape the Mahakanumulla sub cascade

4.6.1. Kunchikulama sub cascade .Location of tanks

4.6.2. Location of tanks and the shape the Kunchikulama sub cascade

4.7.1 Cascade B, its shape and location of tanks

4.7.2. Cascade C and its tank's position
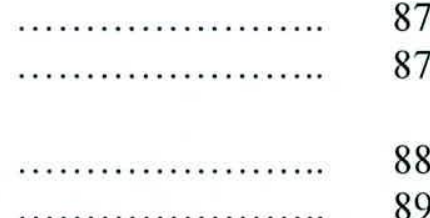

4.7.3. Shape of the Ulankulama sub cascade

4.7.4. Shape of the Wannamaduwa sub cascade

5.1 Functional and abandoned tanks of the cascade A

5.2 Abandoned and working tanks of cascade $\mathrm{A}$ in

5.3 Rainfall trends from 2001 to 2006 
5.4 Tank distribution of cascade B in 1956 and 1994

5.5 Functional status of tanks in cascade B in 1994 and 2001

5.6 Distribution of working and abandoned tanks in the cascade C.

5.7 Topography and drainage systems of the lower part of the cascade $\mathrm{C}$

5.8 Distribution of tanks in the cascade C in 1956 and 2001

5.9.1 Kunchikulama subcascde- dryness of catchment vegetation

5.9.2 Pahalawewa subcascde- dryness of catchment vegetation

5.10 Wamaduwa tank catchment- change of vegetation cover in 2001

5.11 Change in the water spread area of the Meegaswewa tank

5.12 Tanks and dieback and live vegetation of the entire cascade C in 1994

5.13 Topography of the upper parts of the cascade $\mathrm{C}$ and B

6.1 A model showing the water movements of an 164 individual cascade system

6.2 Dry (September) and wet (February) season water yields of the cascade A

6.3 Dry and wet season water yields of the cascade B

6.4 Dry and wet season water yields of the cascade .C

7.1 Position of tanks in the cascade A

7.2 Position of tanks in the cascade B

203

7.3 System functionality of cascade C

207

\section{Plates}

5.1 Full water spread area of Ulankulama sub-cascade in the wet season

5.2 Water spread boundary demarcated by vegetation cover

5.3 Paddy cultivation in the Maha season below the Ulankulama tank

5.4 Water available under vegetation cover in the upper boundary

5.5 Live vegetation around the dried up tank bed 


\section{Appendices}

(i) Basic Landsat Image (1994) used in the study .226

(ii) Basic Landsat Image (2001) used in the study 227

(iii) Nachchaduwa upper basin and the study area .228

(iv) Sample cascades - digital overlying of Canvas GIS on topographical map.....229

(v) Basic information on location of tanks of the study area 230

(vi) Water condition of each tank-CANVAS + MF WORKS-GIS programs 232

(vii) Tank cascade classification .234

(viii)Water yields of sub-cascades of the cascade C in 1994. 235

(ix) Multispec land classification (one program output) 237

(x) Rainfall data pertaining to the study area 238

(xi) Rock outcrops in the catchments of tanks that cause rapid runoff Maradankadawala tank in the cascade C.

(xii) System functionality of the cascade $\mathrm{C}$ 240

(xiii) Long term September and February rainfall pattern of the study area.... 241 


\title{
A Geographical Analysis of Positioning and Functionality of the Tank Cascade Systems of the North Central Province \\ Sri Lanka
}

\author{
by \\ Ganthihe Mudiyanselage Bandaranayake
}

\section{$\underline{\text { ABSTRACT }}$}

Key words: Cascades, Water efficiency, Catchment dryness, Water yield, Water surplus,

\section{Tank water intake}

The cascade tank systems which have been structurally organized within river and stream basins are unique and widely spread phenomena of the Dry Zone landscape of Sri Lanka, where irrigation and water resources management have roots in the early history.

Most studies on tanks and tank cascade systems in Sri Lanka have dealt with the irrigation, water management and environmental aspects, based on individual locations. Morphologically their formation, shape and size and their relation to the water availability from a spatial perspective have not been adequately studied. 
Thus, the present study attempts to comparatively analyze the 'water efficiency of tank cascade systems' using remote sensing, and topographical maps interpretation together with field verifications. To achieve this objective the study observes the distribution and positioning of the tank cascades with emphasise on the physical setup to enable an analysis of water efficiency.

Placing greater emphasis on the spatial aspects of cascades, the study also attempts to differentiate the cascades on the basis of size, shape and destination points of water flow. This classification thus provides an appropriate framework to discuss the location and positioning of the cascades to designate the most efficiencant cascades in the sense of water availability

With the help of the Landsat image interpretation, the study attempts to view the environmental status, in particular the 'dryness' of the tank catchments in order to identify the water and moisture availability of cascades with different shapes to determine which type of cascade is more 'efficient' in maintaining a wet environmental condition.

Quantitatively, the 'cascade water yields' calculated by rainfall and evaporation, and the total tank water capacities are used to determine the most effective cascade types in the sense of water 'deficit' or 'surplus'.

In terms of 'systems theory' the present study also attempts to view how the tank cascades are presently functioning as real systems' with an inter-tank water flow system. In addition, from a social perspective, the people's perception or awareness of the cascading water flow system is used to further confirm the system functionality. 
In sum, with the use of visual information together with quantitative data, the present study provides a basic guidance to identify the most important cascade types on which attention should be focused in the planning of small tank development in the Dry Zone of Sri Lanka. 